\title{
STRATEGI PENGEMBANGAN WISATA MINAT KHUSUS ARUNG JERAM DI SUNGAI CITARUM JAWA BARAT
}

\author{
Nurul Syamsiah ${ }^{1}$, \\ nurulspamilih@stba.ac.id \\ Yudi Satriadi ${ }^{2}$ \\ yudisatriadi@stba.ac.id \\ , Ahmad Fauzul Azhim ${ }^{3}$ \\ ahmadfauzulazhim@gmail.com
}

\begin{abstract}
This study aims to determine the strength, the weaknesses, the opportunities and the threats in the development of special interest tours for rafting on the Citarum River, and to formulate strategies in developing of potential tourist attractions on the Citarum. The research method is the qualitative research. The source of data in the study is the stakeholders of rafting tourism activities on the Citarum. The data are collected by doing observation and by conducting the structured interviews. The data are analyzed using the SWOT analysis method. Based on the IFAS and EFAS results and based on the position of the SWOT diagram, the rafting tour of the Citarum River is in quadrant II, which means although the Citarum rafting tour faces threats, it has good internal strength.
\end{abstract}

Keywords: Special interest tourism, rafting tour, the Citarum River, SWOT analysis 


\section{PENDAHULUAN}

Wisata arung jeram berkembang cukup pesat, apalagi Jawa Barat memiliki banyak sungai yang cukup besar yang dapat dijadikan tempat ideal untuk melakukan wisata arung jeram tersebut. Di Jawab Barat terdapat lebih dari 20 buah sungai dan lebih dari separuhnya dapat dan telah dijadikan tempat berwisata arung jeram.

Di antara sungai-sungai yang selama ini dijadikan lokasi wisata arung jeram, Sungai Citarum adalah salah satunya. Di Jawa Barat Sungai Citarum adalah sungai yang terkenal, karena merupakan sungai terpanjang dan terbesar di propinsi ini. Sungai Citarum mengalir dari hulunya di Gunung wayang di Selatan kota Bandung mengalir ke Utara dan bermuara di laut Jawa. Citarum mengaliri 12 wilayah administrasi kabupaten/kota. Citarum menyuplai air untuk kebutuhan penghidupan 28 Juta masyarakat, Panjang Sungai Citarum secara keseluruhan adalah sekitar $269 \mathrm{~km}$ mengaliri areal irigasi untuk pertanian seluas 420.000 hektar. Citarum juga merupakan sumber dari denyut nadi perekonomian Jawa Barat dengan hamparan industri yang berada di sepanjang aliran sungainya.

Dalam wisata arung jeram, Sungai Citarum adalah sungai yang bersejarah karena di Sungai Citarum inilah kegiatan Arung jeram yang awalnya disebut dengan Olah Raga Arus Deras (Orad) diperkenalkan di Jawa Barat. Di Sungai Citarum inilah sekitar 30 tahun yang lalu untuk pertama kalinya diadakan kompetisi arung jeram yang diberi nama Rally Citarum I. Sampai saat ini pun Sungai Citarum masih sering dijadikan tempat kompetisi arung jeram baik tingkat propinsi maupun tingkat nasional. Sungai Citarum ini juga acap kali dijadikan tempat latihan organisasi-organisasi pencinta alam ketika mereka berlatih arung jeram. Seiring dengan itu, beberapa operator arung jeram, menjual paket wisata arung jeram Sungai Citarum, sehingga di waktu libur biasanya Sabtu dan Minggu sungai ini ramai oleh wisatawan yang berwisata arung jeram.

Agar kegiatan wisata minat khusus arung Jeram Sungai Citarum ini dapat berkembang lebih baik lagi dan dapat menjadi kegiatan wisata unggulan di Jawa Barat khususnya di Kabupaten Bandung Barat, maka sebuah Rencana Strategi kegiatan wisata arung jeram ini haruslah dibuat.

\section{TINJAUAN PUSTAKA}

\section{Pemahaman tentang Pariwisata}

Pariwisata berasal dari bahasa Sansekerta yaitu kata "Pari" yang berarti halus, maksudnya mempunyai tata krama tinggi dan "wisata" yang berarti kunjungan atau perjalanan untuk melihat, mendengar, menikmati dan mempelajari sesuatu (Syafiie, 2008). Menurut Kodhyat (1983) pariwisata adalah perjalanan dari suatu tempat ke tempat lain, bersifat sementara, dilakukan perorangan atau kelompok, sebagai usaha mencari keseimbangan atau keserasian dan kebahagian dengan lingkungan dalam dimensi sosial, 
budaya, alam dan ilmu. Selanjutnya Burkart dan Medlik (1987) menjelaskan pariwisata sebagai suatu trasformasi orang untuk sementara dan dalam waktu jangka pendek ke tujuantujuan di luar tempat di mana mereka biasanya hidup dan bekerja, dan kegiatan-kegiatan mereka selama tinggal di tempat-tempat tujuan itu.

Definisi pariwisata menurut WTO (dalam Ismayanti, 2010) " activities of person travelling to anda staying in place outside their usual environment for not more than one consecutive year for leisure, bussines and other purposes". Sedangkan Wahab (1989) menjelaskan pariwisata adalah salah satu jenis industri baru yang mampu menghasilkan pertumbuhan ekonomi yang cepat dalam penyediaan lapangan kerja, peningkatan penghasilan, standart hidup serta menstimulasi sektor-sektor produktivitas lainnya. Sebagai sektor yang kompleks, pariwisata juga meliputi industri-industri klasik seperti kerajinan tangan dan cinderamata, penginapan, transportasi secara ekonomi juga dipandang sebagai industri

\section{Pengembangan Objek Wisata}

Fandeli (2012) mengemukakan bahwa pengembangan pariwisata pada dasarnya adalah pengembangan masyarakat dan wilayah yang didasarkan pada:

1. Memajukan tingkat hidup masyarakat sekaligus melestarikan identitas dan tradisi lokal.

2. Meningkatkan tingkat pendapatan secara ekonomis sekaligus mendistribusikan secara merata kepada penduduk lokal.

3. Berorientasi kepada pengembangan wisata berskala kecil dan menengah dengan daya serap tenaga kerja besar dan berorientasi pada teknologi kooperatif.

4. Memanfaatkan pariwisata seoptimal mungkin sebagai agen penyumbang tradisi budaya dengan dampak negatif yang seminimal mungkin.

Pengembangan pariwisata memerlukan teknik perencanaan yang baik dan tepat. Teknik perencanaan itu harus menggabungkan beberapa aspek penunjang kesuksesan pariwisata. Aspek-aspek tersebut adalah aspek aksesbilitas (transportasi dan saluran pemasaran), karakteristik infrastuktur pariwisata, tingkat interaksi sosial, keterkaitan/ kompatibilitas dengan sektor lain, daya tahan akan dampak pariwisata, tingkat resistensi komunitas lokal, dan seterusnya (Pitana, 2009).

Perencanaan dan pengembangan pariwisata merupakan suatu proses yang dinamis dan berkelanjutan menuju ketataran nilai yang lebih tinggi dengan cara melakukan penyesuaian dan koreksi berdasar pada hasil monitoring dan evaluasi serta umpan balik implementasi rencana sebelumnya yang merupakan dasar kebijaksanaan dan merupakan misi yang harus dikembangkan. Perencanaan dan pengembangan pariwisata bukanlah system yang berdiri sendiri, melainkan terkait erat dengan sistem perencanaan pembangunan yang lain secara inter sektoral dan inter regional.

Perencanaan pariwisata haruslah didasarkan pada kondisi dan daya dukung dengan maksud menciptakan interaksi jangka panjang yang saling menguntungkan di antara pencapaian tujuan pembangunan pariwisata, peningkatan kesejahteraan masyarakat setempat, dan berkelanjutan daya dukung lingkungan di masa mendatang (Fandeli,2012). 


\section{Wisata Minat Khusus}

Special Interest Tourism atau dalam bahasa Indonesia umum dikenal dengan sebutan pariwisata minat khusus merupakan jenis pariwisata di mana wisatawan melaksanakan perjalanan untuk belajar dan berupaya mendapat pengalaman baru tentang sesuatu hal di daerah yang dikunjungi. Bahkan ada pula yang mengatakan bahwa tipologi dari wisata jenis ini tidak biasa, anti mainstream, atau bahkan aneh. Disebut aneh, karena biasanya wisata minat khusus sangat berhubungan dengan hobi seseorang, komunitas, atau didasari rasa ingin tahu yang sangat tinggi. Wisata minat khusus merupakan kegiatan wisata yang memiliki permintaan di luar permintaan wisatawan lainnya. Wisatawan minat khusus biasanya memilih perjalanan wisata yang sesuai dengan latar belakang pekerjaan, hobi maupun intelektualitas. Dalam mempersiapkan layanan jasa untuk wisatawan minat khusus diperlukan perencanaan yang khusus pula, serta biaya yang dibutuhkan relatif lebih mahal dari pada perjalanan wisata lainnya (Marpaung, 2002).

Novelli (2005) mengatakan bahwa wisata minat khusus dapat diartikan sebagai sebuah bentuk pariwisata yang melibatkan pengunjung dengan motivasi tertentu dan mengejar kepuasan yang ditentukan oleh pengalaman yang didapat selama kegiatan wisata dilakukan. Sesuai dengan namanya, orang-orang yang melakukan wisata minat khusus biasanya berkeinginan untuk mewujudkan minat dan ketertarikannya terhadap suatu objek atau hal yang lain. Oleh karena itu, umumnya wisata ini hanya diikuti oleh satu, dua, atau sekelompok kecil pelancong.

\section{Arung Jeram sebagai Kegiatan Wisata Minat Khusus}

Menurut Darsono dan Setria (2008), dalam Suganda Roni (2014) arung jeram adalah aktivitas pengarungan bagian alur sungai yang berjeram atau riam dengan menggunakan wahana tertentu. Pengertian wahana dalam hal ini adalah sarana atau alat yang terdiri atas perahu karet, kayak, kano, dan dayung. Tujuan berarung jeram bisa dilihat dari sisi olahraga, rekreasi, dan ekspedisi. Dengan demikian dapat didefinisikan olahraga arung jeram sebagai olahraga mengarungi sungai berjeram dengan menggunakan perahu karet, kayak, kano dan dayung dengan tujuan rekreasi atau ekspedisi.

Arung jeram telah menjadi aktivitas luar ruangan yang populer karena dapat dinikmati beramai-ramai tanpa memandang usia, status sosial, tingkat pendidikan, dan profesi seseorang. Di Indonesia pun semakin banyak sungai yang dapat diarungi serta dikelola secara profesional. Mereka menawarkan berbagai paket pengarungan sesuai dengan tingkatan umur dan kemampuan calon pesertanya. Wisata arung jeram (White-water rafting) termasuk ke dalam hard adventure activities (Amelda \& Rudyanto, 2012). Menurut Millington et al. (2001) hard adventure activities selain membutuhkan pengalaman dan keahlian dalam suatu kegiatan. juga membutuhkan sebuah elemen pengalaman dari kegiatan yang dijalankan. Oleh karena kegiatan tersebut meliputi elemen resiko maka peserta harus sehat secara fisik dan mental, juga harus menyiapkan diri untuk menghadapi berbagai kondisi cuaca dan keadaan. 


\section{METODE PENELITIAN}

Metode penelitian yang digunakan adalah menggunakan metode kualitatif. Penelitian kualitatif sebagaimana yang diungkapkan Bogdan dan Taylor (L.J. Maleong, 2011:4) sebagai prosedur penelitian yang menghasilkan data deskriptif berupa katakata tertulis atau lisan dari orang-orang dan perilaku yang dapat diamati. Selain itu, metode penelitian kualitatif, menurut Nana Syaodih (2007) adalah cara untuk mendeskripsikan dan menganalisis fenomena, peristiwa, aktivitas sosial, sikap kepercayaan, persepsi, pemikiran orang secara individual maupun kelompok.

\section{Sumber Data}

Yang menjadi sumber data dalam penelitian ini adalah stake holder kegiatan wisata arung jeram di Sungai Citarum, antara lain para operator pengelolan kegiatan wisata arung jeram yang ada, guide arung jeram, masyarakat di sekitar lokasi tempat kegiatan arung jeram dilaksanakan serta wisatawan yang pernah berwisata arum jeram di Sungai Citarum.

\section{Metode Pengumpulan Data}

Dalam penelitian ini data akan dikumpulkan dengan dua cara yaitu dengan cara observasi, terutama untuk mengetahui kondisi dan potensi alam, kedua dengan melakukan wawancara terstruktur terhadap stake holder wisata arung jeram Sungai Citarum.

\section{Teknik Analisis Data}

Permasalahan dalam penelitian ini akan dianalisis dengan metode analisis SWOT dengan pendekatan kuantitatif, analisis IFAS (Internal Factors Analisys Summary) dan EFAS (External Factors Analisys Summary) serta analisis SWOT (Strengths Weaknesses Opportunities Thereats) untuk merancang strategi pengembangannya, setelah itu dibuat Positioning Kuadran SWOT untuk mengetahui posisi potensi Wisata Arung Jeram di Sungai Citarum.

SWOT merupakan sebuah alat analisis yang cukup baik, efektif dan efisien serta sebagai alat yang cepat dalam menemukan kemungkinan yang berkaitan dengan pengembangan awal program-program inovasi baru dalam kepariwisataan. Sifat analisis SWOT sangat situasional, dalam artian hasil analisis tahun sekarang belum tentu akan sama dengan hasil analisis tahun yang akan datang, pengaruh faktor ekonomi, politik, kemanan dan keadaan sosial yang melatarbelakanginya menyebabkan adanya perubahan (Rahman,AM. 2010)

A. Yoeti (1996) memaparkan bagaimana analisis SWOT dalam sekenario pengembangan pariwisata adalah sebagai berikut:

1. Kekuatan (Strength)

Mengetahui kekuatan pariwisata suatu wilayah sehingga mampu bertahan dalam pasar dan mampu bersaing untuk pengembangan selanjutnya. 
2. Kelemahan (Weakness)

Segala faktor yang tidak menguntungkan atau merugikan bagi sektor pariwisata.

3. Kesempatan (Opportunity)

Semua kesempatan yang ada sebagai akibat kebijakan pemerintah, peraturan yang berlaku atau kondisi perekonomian.

4. Ancaman (Threats)

Ancaman dapat berupa hal-hal yang dapat mendatangkan kerugian bagi pariwisata, seperti peraturan yang tidak memberikan kemudahan dalam berusaha, rusaknya lingkungan, dan lain sebagainya.

\section{HASIL PENELITIAN DAN PEMBAHASAN}

\section{Analisis SWOT Wisata Arung Jeram di Sungai Citarum}

Langkah pertama dari analisis SWOT adalah mengindentifikasi faktor internal dan faktor ekternal dari kegiatan wisata arung jeram di Sungai Citarum. Faktor internal terdiri dari Kekuatan dan Kelemahan, sedangkan factor ekternal terdiri dari peluang dan ancaman.

Berdasarkan hasil analisis data yang telah dilakukan, hasil inventarisasi factor internal adalah sebagai berikut :

1. Kekuatan

a. Aksesibilitas Lokasi

Aksesibilitas lokasi arung jeram sungai Citarum baik itu lokasi start maupun lokasi finish sangat baik dalam arti sangat mudah didatangi. Selain tidak jauh dari pusat-pusat kegiatan, jalan menuju ke lokasi juga kondisinya baik, bisa dengan mudah dilalui semua jenis kendaraan bermotor roda empat maupun roda dua.

b. Keamanan dalam Melakukan Kegiatan

Lokasi arung jeram di sungai Citarum adalah aman, sehingga wisata arung jeram di Sungai Citarum dapat dilakukan baik oleh anak-anak, remaja maupun orang dewasa. Termasuk wisatawan yang belum pernah berarung jeram sama sekali maupun wisatawan yang tak bisa berenang.

c. Biaya Terjangkau

Biaya yang harus dikeluarkan oleh wisatawan untuk berarung jeram di sungai Citarum, relatif lebih murah dibanding biaya yang harus dikeluarkan bila berarung jeram di tempat yang lain. Aksebilitas lokasi yang tidak terlalu jauh dan jalan yang mulus menuju lokasi adalah penyebab biaya berwisata arung jeram di sungai Citarum relatif terjangkau.

d. Lokasi wisata dapat dijadikan lokasi untuk kegiatan pelatihan dan kejuaraan arung jeram.

2. Kelemahan

a. Sungai seringkali berbau tak sedap. 
Sungai Citarum adalah salah satu sungai yang tercemar di Indonesia, karena sebagian besar masyarakat yang tinggal di pinggir sungai dan pabrik masih membuang sampah termasuk atau limbahnya.

b. Sarana dan Prasana Penujang Kegiatan Tidak Lengkap.

Belum ada bangunan khusus tempat kantor pengelola memberikan layanan pada wisatawan, belum ada ruang tunggu, ruang ganti pakaian maupun toilet yang memadai untuk digunakan wisatawan, demikian juga belum ada tempat parkir khusus kendaraan. Selama ini faslilitas yang digunakan biasanya adalah fasilitas milik penduduk.

c. Pemandu Belum Bersertifikat

Pemandu wisata arung jeram selain harus terlatih dan berpengalaman juga sebenarnya harus memiliki sertifikat profesi yang dikeluarkan oleh BNSP.

d. Belum Ada Operator Tetap.

Sampai saat ini tidak memiliki operator arung jeram yang menempati base camp secara tetap dan permanen di lokasi kegiatan arung jeram dilakukan.

Sedangkan, hasil inventarisasi faktor ekternal adalah sebagai berikut :

3. Peluang

a. Program Citarum Harum.

Program Citarum Harum adalah program Nasional yang dicanangkan oleh pemerintah pusat pada tahun 2018 melalui Peraturan Presiden Nomor 15/2018 tentang Percepatan Pengendalian Pencemaran dan Kerusakan Daerah Aliran Sungai Citarum. Tujuan Program Citarum bersih pada dasarnya adalah untuk menyelamatkan ekosistem sungai Citarum. Adanya program Citarum Harum ini langsung maupun tidak langsung membuat kualitas air sungai Citarum semakin lama semakin baik, hal ini tentu saja membuka peluang semakin banyaknya wisatawan berwisata arung jeram di sungai Citarum

b. Berkembangnya Gaya Hidup Berwisata.

c. Dukungan Masyarakat Sekitar.

Masyarakat sekitar umumnya mendukung karena secara tidak langsung kegiatan wisata arung jeram ini mendorong pertumbuhan ekonomi secara lokal.

d. Dekat dengan Objek Wisata Lainnya

Tidak terlalu jauh dari objek-objek wisata lainnya, dalam radius $3 \mathrm{Km}$, dari terdapat obyek wisata pemadian air panas dan obyek wisata Sanghiang Heulet, objek wisata Cikahuripan dan DAM Saguling.

\section{Ancaman}

a. Proyek PLTA Saguling II

Proyek PLTA Saguling II, saat ini sedang dikerjakan, keberadaan PLTA Saguling II ini nantinya menyebabkan sebagian aliran air sungai dibelokkan ke instalasi PLTA agar aliran air dapar mendorong turbin air dan menghasilkan listrik, hal itu 
akan mengakibatkan aliran sungai tempat lokasi wisata arung jeram Sungai Citarum akan berubah.

b. Belum Ditetapkan Sebagai Destinasi Wisata

Sampai saai ini, pemerintah daerah baik pemerintah provinsi Jawa Barat, maupun pemerintah kabupaten Bandung Barat (KBB) belum secara resmi menetapkan lokasi ini sebagai destinasi wisata.

c. Degradasi dan Kerusakan Lingkungan

Hal ini dapat menyebabkan keindahan pemandangan saat berwisata arung jeram di Sungai Citarum menjadi berkurang.

d. Berkembang Wisata Sejenis yang Jaraknya Tidak Terlalu Jauh.

Tidak terlalu jauh dari lokasi wisata arung jeram sungai citarum, ada sungai Cisokan. Sungai Cisokan terletak di Kabupaten Cianjur yang jaraknya Kurang lebih $10 \mathrm{Km}$ dari Lokasi arung Jeram Sungai Citarum.

\section{IFAS DAN EFAS}

Analisis internal dilakukan untuk mendapatkan faktor kekuatan yang akan dipergunakan dan faktor kelemahan yang akan diantisipasi. Untuk mengevaluasi faktor tersebut digunakan matriks IFAS (Internal Factor Analysis Summary).

Berikut adalah matrik IFAS wisata arung jeram Sungai Citarum.

Tabel 1. Matrix IFAS Wisata Arung Jeram Sungai Citarum

\begin{tabular}{|c|c|c|c|c|}
\hline No & Faktor strategi & Bobot & Rangking & $\begin{array}{c}\text { Nilai } \\
\text { (Bobot } x \text { Rangking) }\end{array}$ \\
\hline \multicolumn{5}{|c|}{ KEKUATAN } \\
\hline 1 & Aksesibilitas lokasi & 0.30 & 4 & 1.20 \\
\hline 2 & Keamanan dalam melakukan kegiatan & 0.40 & 4 & 1.60 \\
\hline 3 & Biaya terjangkau & 0.20 & 2 & 0.40 \\
\hline \multirow[t]{2}{*}{4} & $\begin{array}{l}\text { Lokasi wisata dapat dijadikan lokasi } \\
\text { untuk kegiatan pelatihan dan kejuaraan } \\
\text { arung jeram }\end{array}$ & 0.10 & 1 & 0.10 \\
\hline & & $\mathbf{1 . 0 0}$ & & 3.30 \\
\hline \multicolumn{2}{|c|}{ KELEMAHAN } & & & - \\
\hline 5 & Sungai seringkali berbau tak sedap & 0.40 & 2 & 0.80 \\
\hline 6 & $\begin{array}{l}\text { Sarana dan prasana penujang kegiatan } \\
\text { tidak lengkap }\end{array}$ & 0.35 & 3 & 1.05 \\
\hline 7 & Pemandu belum bersertifikat & 0.15 & 2 & 0.30 \\
\hline \multirow[t]{2}{*}{8} & Belum ada operator tetap & 0.10 & 2 & 0.20 \\
\hline & & 1.00 & & 2.35 \\
\hline
\end{tabular}

Seperti juga untuk factor internal, factor Ekternal yaitu factor Peluang dan Ancaman dievaluasi dengan menggunakan matrik EFAS (External Factors Analisys Summary). Berikut adalah matrik EFAS wisata arung jeram Sungai Citarum.

Tabel 2. Matrik EFAS Wisata Arung Jeram Sungai Citarum 


\begin{tabular}{|c|l|r|r|r|}
\hline No & \multicolumn{1}{|c|}{ Faktor strategi } & Bobot & Rangking & $\begin{array}{c}\text { Nilai } \\
\text { (Bobot x Rangking) }\end{array}$ \\
\hline PELUANG & & & 0.75 \\
\hline 1 & Program Citarum Harum. & 0.25 & 3 & 0.60 \\
\hline 2 & Berkembangnya gaya hidup berwisata & 0.30 & 2 & 0.90 \\
\hline 3 & Dukungan Masyarakat sekitar & 0.30 & 3 & 0.15 \\
\hline 4 & Dekat dengan objek wisata lainnya & 0.15 & 1 & $\mathbf{2 . 4 0}$ \\
\hline & \multicolumn{1}{|c|}{1.00} & & 1.35 \\
\hline ANCAMAN destinasi & 0.15 & 2 & 0.30 \\
\hline 5 & Proyek PLTA Saguling II & & & 0.40 \\
\hline 6 & $\begin{array}{l}\text { Belum ditetapkan sebagai } \\
\text { wisata oleh PP }\end{array}$ & 0.20 & 2 & 0.40 \\
\hline 7 & $\begin{array}{l}\text { Degradasi dan kerusakan lingkungan } \\
\text { Berkembang wisata sejenis yang } \\
\text { jaraknya tak terlah jauh. }\end{array}$ & 0.20 & 2 & $\mathbf{2 . 4 5}$ \\
\hline & \multicolumn{1}{|c|}{} & & 3 & \\
\hline
\end{tabular}

\section{Posotioning Kuadran SWOT}

Berdasarkan matrik IFAS dan EFAS tersebut di atas, dapat diketahui posisi sumbu $X$ dan posisi sumbu $Y$ yang dimana menentukan posisi di kuadran SWOT. Dari matrik IFAS dapat diketahui posisi sumbu $X$ dengan rumus sebagai berikut:

$$
\mathrm{X}=\text { Total kekuatan }- \text { total Kelemahan }
$$

Sedangkan untuk matrik EFE dapat diketahui posisi sumbu Y dengan rumus sebagai berikut:

$$
\begin{aligned}
& \mathrm{Y}=\text { Total Peluang }- \text { total Ancaman } \\
\mathrm{X} & =\text { Total kekeuatan }- \text { Total kelemahan } \\
& =3.0-2.35=0.95 \\
\mathrm{Y} \quad & \text { Total Peluang }- \text { Total Ancaman } \\
= & 2.40-2.45=-0.05
\end{aligned}
$$

Berdasarkan matriks IFE dan matriks EFE, dapat diketahui posisi pada sumbu X pada titik 0.95 dan posisi sumbu $Y$ berada pada titik -0.05 Berikut dibawah ini adalah gambar yang menunjukan positioning pengembangan wisata arung jeram Sungai Citarum 


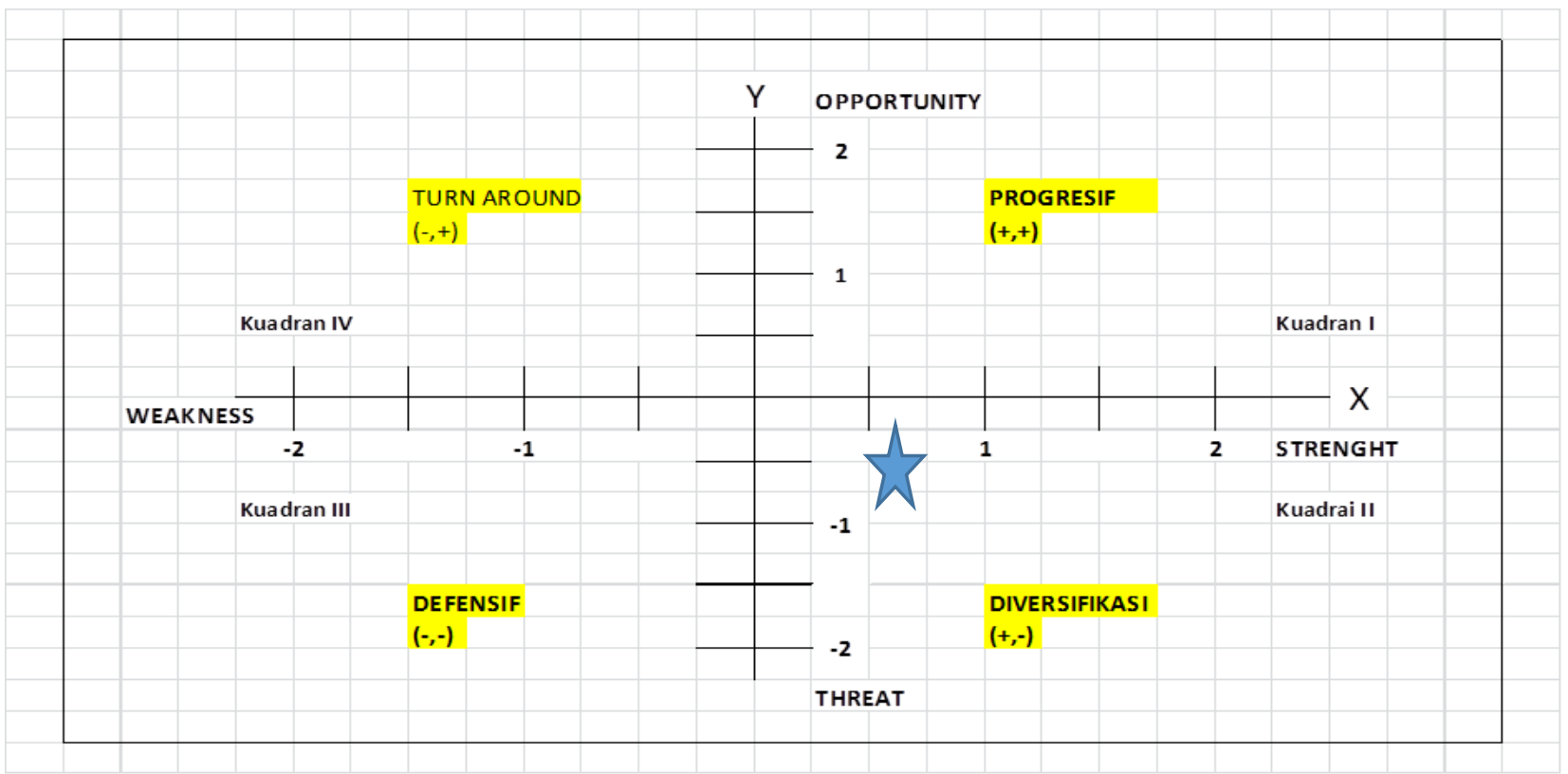

\section{Gambar 1. Diagram SWOT Wisata Arung Jeram Sungai Citarum}

\section{Strategi Pengembangan Wisata Arung Jeram di Sungai Citarum}

Gambar 1 menunjukan bahwa positioning wisata arung jeram sungai Citarum pada diagram SWOT berada pada kuadran ke dua. Artinya Wisata arung jeram Sungai Citarum ini mempunyai kekuatan internal yang baik akan tetapi harus menghadapi ancaman eksternal yang cukup besar, oleh karena itu strategi yang digunakan adalah strategi Difersifikasi. Strategi difersifikasi dikenal juga dengan sebutan strategi S-T, yaitu strategi dimana mengoptimalkan kekuatan (Strength) untuk mengatasi ancaman (Threat). Strategi ini juga berarti strategi menghindari atau mengurangi dampak dari ancaman-ancaman eksternal.

Rencana strategi yang dapat dilakukan sebagai strategi S-T untuk pengembangan wisata arung jeram di sungai Citarum adalah seperti pada matrik strategi S-T berikut. 
Tabel 3. Matrik Strategi S-T Pengembangan Wisata Arung Jeram Sungai Citarum

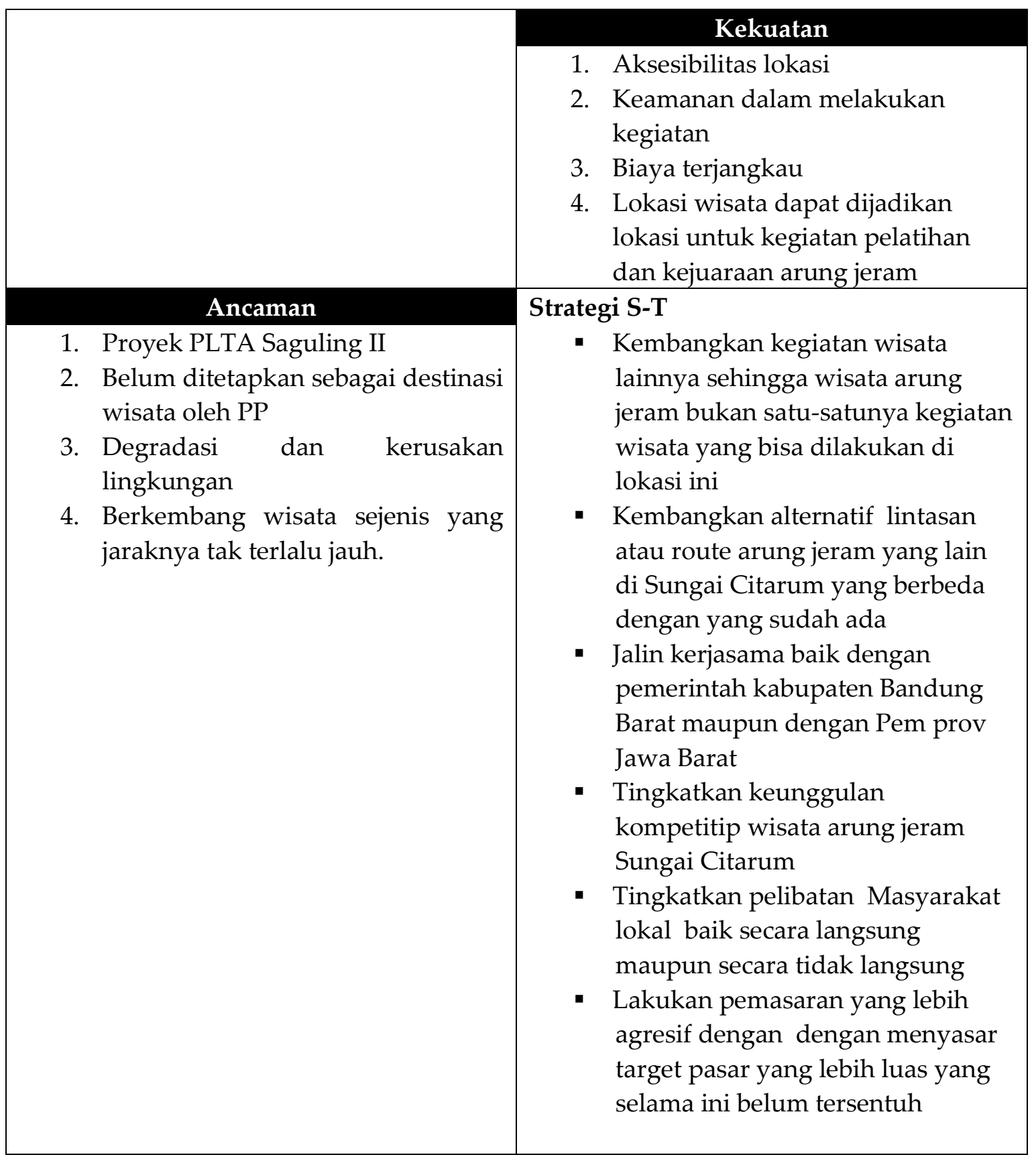

1. Kembangkan kegiatan wisata lainnya sehingga wisata arung jeram bukan satusatunya kegiatan wisata yang bisa dilakukan di lokasi tersebut. Mengembangkan wisata cross country, wisata paint ball, wisata perdesaan dan wisata lainnya yang 
melibatkan penduduk lokal, sehingga wisatawan yang pernah datang ke lokasi untuk berarung jeram akan datang lagi untuk mencoba jenis wisata lain yang ada di lokasi tersebut. Di Lokasi wisata ini juga bisa juga dikembangkan kegiatan pelatihan seperti sekolah arung jeram untuk mereka yang ingin berlatih arung jeram secara lebih mendalam.

2. Kembangkan alternatif lintasan atau rute arung jeram yang lain di Sungai Citarum yang berbeda dengan yang sudah ada. Lintasan atau route alternative ini juga dibutuhkan bila karena adanya proyek PLTA Saguling II. lintasan atau rute arung jeram yang selama ini digunakan tidak dapat lagi digunakan.

3. Jalin kerjasama baik dengan pemerintah Kabupaten Bandung Barat maupun dengan pemerintah Provinsi Jawa Barat. Dukungan dari pemerintah diperlukan agar lokasi wisata ini dapat dikembangkan dengan menggunakan fasilitas dari pemerintah.

4. Tingkatkan keunggulan kompetitif wisata arung jeram Sungai Citarum

5. Tingkatkan pelibatan masyarakat lokal baik secara langsung maupun tidak langsung dalam membangkitkan kesadaran tentang pentingnya pariwisata juga menumbuh-kembangkan kreatifitas yang melahirkan berbagai kreasi segar yang mengundang perhatian untuk kemudian menjadi daya pikat pariwisata.

5. Lakukan pemasaran yang lebih agresif dengan menyasar target pasar yang lebih luas yang selama ini belum tersentuh. Pemasaran tidak hanya dapat dilakukan melalui reklame yang ada di pinggir jalan. Pemasaran juga dapat dilakukan melalui sosial media seperti facebook, instagram dan lain sebagainya. Terkenalnya suatu tempat wisata di kalangan para wisatawan tergantung pada proses pemasarannya.

\section{KESIMPULAN}

Berdasarkan paparan hasil penelitian dan pembahasan yang telah disajikan, maka

Dari penelitian ini dapat disimpulkan hal-hal sebagai berikut :

1. Berdasarkan Hasil IFAS dan EFAS dan berdasarkan posisioning pada diagram SWOT, wisata arung jeram sungai Citarum ada pada kuadran II, artinya meskipun wisata arung jeram sungai Citarum menghadapi ancaman, tetapi memiliki kekuatan internal yang baik. oleh karena itu strategi yang digunakan adalah strategi difersifikasi. Strategi difersifikasi dikenal juga dengan sebutan strategi S-T, yaitu strategi dimana mengoptimalkan kekuatan (Strength) untuk mengatasi ancaman (Threat). Strategi ini juga berarti strategi menghindari atau mengurangi dampak dari ancaman-ancaman eksternal.

2. Rencana strategi yang dapat di lakukan untuk mengembangkan wisata arung jeram Sungai Citarum adalah: 1) Kembangkan kegiatan wisata lainnya sehingga wisata arung jeram bukan satu-satunya kegiatan wisata yang bisa dilakukan di lokasi ini; 2) Kembangkan alternatif lintasan atau route arung jeram yang lain di Sungai Citarum 
yang berbeda dengan yang sudah ada; 3) Jalin kerjasama baik dengan pemerintah Kabupaten Bandung Barat maupun dengan pemerintah provinsi Jawa Barat: 4)Tingkatkan keunggulan kompetitip wisata arung jeram Sungai Citarum; 5) Tingkatkan pelibatan Masyarakat lokal baik secara langsung maupun secara tidak langsung; 6) Lakukan pemasaran yang lebih agresif dengan dengan menyasar target pasar yang lebih luas yang selama ini belum tersentuh

\section{DAFTAR PUSTAKA}

A.Yoeti, Oka. (1996). Pengantar Ilmu Pariwisata. Angkasa: Bandung. Amelda \& Rudyanto (2012) Kajian Literatur Wisata Petualangan , HOSPITOUR VOLUME III No. 2 - Oktober 2012

Fandeli, Chafid. 2012. Dasar-Dasar Manajemen Kepariwisataan Alam. Yogyakarta : Liberti

Ismayanti. (2010). Pengantar Pariwisata. Jakarta: PT Gramedia Widisarana Indonesia Kodhyat, H. (1983). Sejarah Pariwisata dan Perkembangannya di Indonesia. Jakarta: PT. Gramedia Pustaka Utama

Marpaung, Happy dan Bahar Herman. (2002), Pengantar Pariwisata,Penerbit Alfabeta, Bandung

Millington, K., Locke, T. and Locke, A. (2001). Occasional studies: adventure travel.Travel and Tourism Analyst, 4, 65-97.

Moleong, L.J. (2011). Metodologi Penelitian Kualitatif Edisi Revisi. Bandung: PT Remaja Rosdakarya.

Nana Syaodih Sukmadinata. (2007). "Metode PenelitianPendidikan, (Bandung: PT. Remaja Rosdakarya

Novelli, M. (2005). Niche Tourism, contemporary issues, trends and cases. UK: Routledge.

Pitana, I Gde. dan Surya Diarta, I Ketut. (2009). Pengantar Ilmu Pariwisata. Yogyakarta: Penerbit Andi.

Rahman,AM. 2010. Analisis Strategi Pengembangan Kawasan Wisata DalamPeningkatan Kesejahteraan Masyarakat Di Kecamatan Pantai CerminKabupaten Serdang Bedagai. Tesis. Sekolah Pascasarjana Universitas Sumatera Utara. Medan

Suganda, Roni (2014) Suvei Perkembangan Wisata Ancol Arung Jeram Desa Buluh Duri Kecamatan Sipispis Kabupaten Serdang Bedagai Sebagai Pengelola Wisata Arung Jeram Tahun 2014. Undergraduate thesis, UNIMED.

Syafiie, Inu Kencana. 2001. Filsafat Pemerintah. Jakarta: PT.Perca

Wahab, Salah. (1989). Manajemen Kepariwisataan.Pradya Paramita. Jakarta 
